\title{
The morphodynamics of tidal sand waves: A model overview
}

\author{
G. Besio $^{\mathrm{a}, *}$, P. Blondeaux ${ }^{\mathrm{a}}$, M. Brocchini ${ }^{\mathrm{b}}$, S.J.M.H. Hulscher ${ }^{\mathrm{c}}$, D. Idier ${ }^{\text {d }}$, M.A.F. Knaapen ${ }^{\mathrm{c}}$, \\ A.A. Németh ${ }^{\text {c, }}$, , P.C. Roos ${ }^{c}$, G. Vittori ${ }^{\text {a }}$ \\ a Department of Civil, Environmental and Architectural Engineering, University of Genoa, Via Montallegro, 1 - 16145, Genova, Italy \\ ${ }^{\mathrm{b}}$ Institute of Hydraulics and Road Infrastructures, Polythecnic University of Marche, V. Brecce Bianche 12 - 60131 Ancona, Italy \\ ${ }^{c}$ Water Engineering and Management, Faculty of Engineering, University of Twente, PO box 217, 7500AE Enschede, The Netherlands \\ d BRGM, Service Aménagement et Risques Naturels, (ARN/ESL), 3, avenue C. Guillemin, 45006 Orléans Cedex 2, France
}

Received 12 May 2006

Available online 22 January 2008

\begin{abstract}
This paper reviews recent theoretical studies of sand waves which are rhythmic large-scale bedforms observed in the continental shelf far from the near-shore region. Emphasis is given to the investigations carried out in the framework of the EU research project HUMOR. First, the results of linear morphodynamic stability analyses are described, which allow to understand the initial behavior of the sand waves. Hence, indications on the physical processes controlling the appearance and development of sand waves are obtained along with quantitative predictions of the wavelength of sand waves and of their migration speed. Then, nonlinear models are described which are used to predict the equilibrium profile of sand waves and their interaction with human interventions like sand extraction or the construction of pipelines. Finally, we discuss an analytical model which describes how the sand wave instability behaves when it is triggered locally; this leads to the generation, growth and expansion of a so-called sand wave packet.
\end{abstract}

(C) 2007 Elsevier B.V. All rights reserved.

Keywords: Morphodynamics; Tidal bedforms; Sand waves

\section{Introduction}

Large parts of the sea bed of shallow shelf seas, such as the North Sea, are covered with bottom forms, which are fascinatingly regular. Indeed, a common property of many morphological features observed in the continental shelf is that they are repetitive both in space and in time, so that typical wavelengths, amplitudes and migration speeds can be assigned to them. In particular, field observations in tide-dominated areas indicate the presence of symmetrical and asymmetrical sand

\footnotetext{
* Corresponding author.

E-mail addresses: giospud@diam.unige.it (G. Besio),blx@diam.unige.it (P. Blondeaux), s.j.m.h.hulscher@utwente.nl (S.J.M.H. Hulscher), d.idier@grgm.fr (D. Idier), p.c.roos@utwente.nl (P.C. Roos).

${ }^{1}$ Present Address: Saxion Universities of Applied Sciences, School of Environmental Planning and Building, P.O. Box 501, 7400 AM Deventer, The Netherlands.
}

waves with crests almost perpendicular to the direction of the main tidal current (see Fig. 1) and characterized by wavelengths of the order of hundreds of meters and amplitudes of a few meters.

Sand waves are quite important from an engineering point of view, because they are not static. Instead, they migrate under the action of a residual current (Németh et al., 2002) or because of tide asymmetry (Besio et al., 2004). The residual current can originate either from the tide, either from a wind-induced current (Idier et al., 2002), or from wave-induced current which can lead to tidal cycles without any reverse of the current.

Many human activities are confronted with the presence of migrating sand waves. Sand wave migration can represent a serious hazard to, for instance, pipelines. Several examples can be found of free spans related to the formation and migration of sand waves (see Fig. 2). Moreover, intense dredging activities may be required because of sand waves decreasing the least navigable depths (Knaapen et al., 2001). Furthermore, they can 


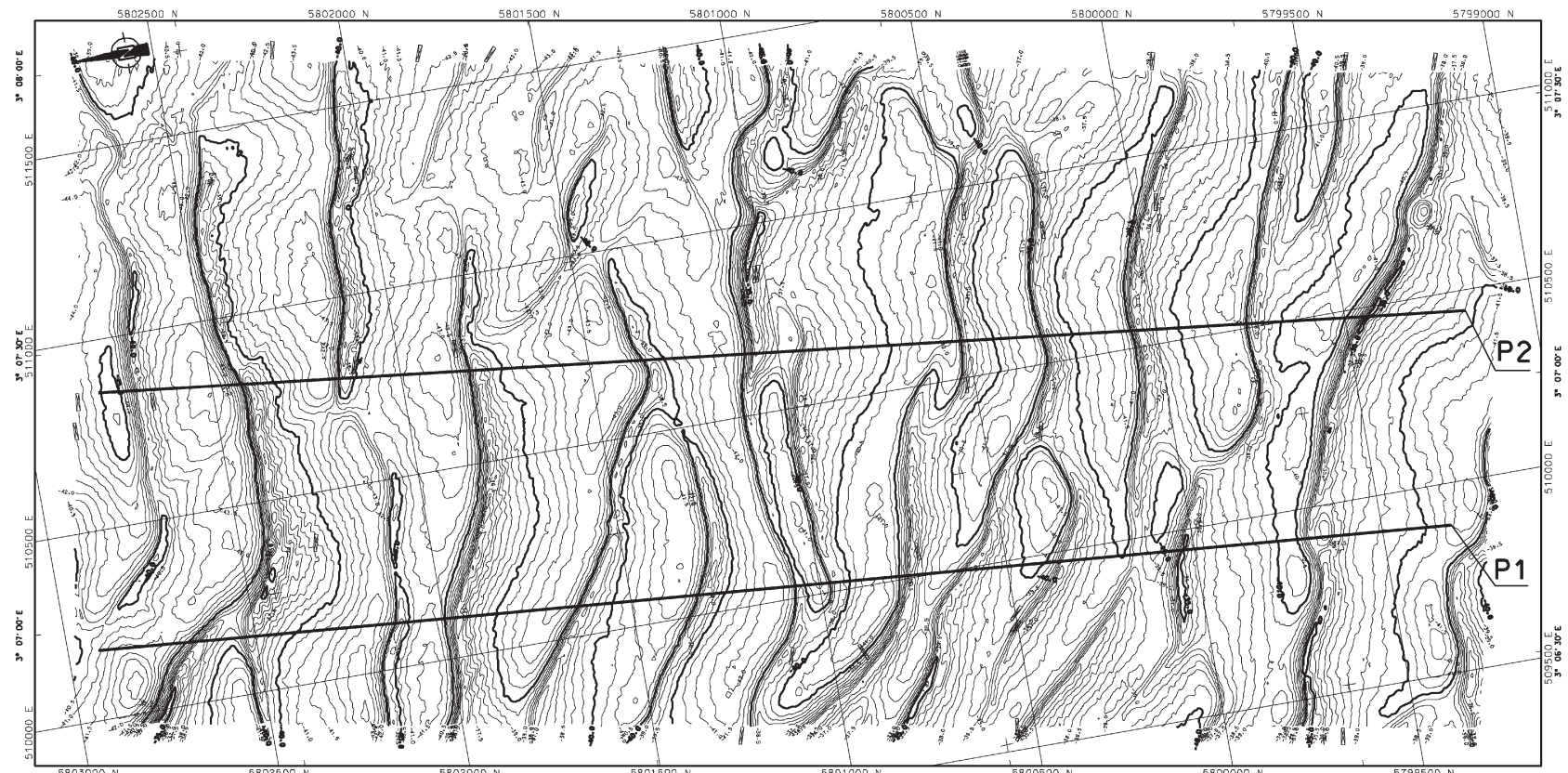

Fig. 1. Bottom topography measured in the North Sea at $52^{\circ} 21^{\prime} \mathrm{N}$ and $3^{\circ} 9^{\prime}$ showing the presence of sand waves. The grid size is $500 \mathrm{~m}$. Courtesy of SNAMPROGETTI S.p.A (Adapted from Besio et al., 2006).

also migrate into shipping channels and harbors, which reduces the local water depth and consequently the navigability (Trentesaux and Garlan, 2000; Knaapen et al., 2001; Németh et. al., 2003; Roos et al., 2005).

Németh et al. (2003) identified some engineering problems related to the dynamics of sand waves. Here we summarize their finding and identify how the current state of the art on sand wave modeling can help solving these issues.

In the Euro Channel to Rotterdam Harbor, sand waves reduce the navigable depth to an unacceptable level. To avoid the risk of grounding, the navigation depth is monitored and sand waves that reduce the navigation depth unacceptably are dredged. After the dredging, the sand waves slowly regain their original height. To reduce the required amount of surveys and provide optimal information on the necessity to dredge, the North Sea Service of the Department of Transport, Public Works and Water Management, is implementing a Decision
Support System. Currently, the system predicts the growth of sand waves using a linear trend. The trend is determined from observations using a Kalman-filter including geo-statistical components to incorporate spatial dependencies. This procedure works well for sand waves that are close to their maximum height. However, after dredging, the sand wave height is far from its equilibrium and the growth rate is much higher, making the linear prediction worthless. Knaapen et al. (2005) showed that replacing the linear trend with a Landau model for sand waves improves the predictions of the regeneration. Indeed a comparison between observations and predictions shows that the Landau model predicts the crest evolution better than the linear model both for undisturbed sand waves and dredged sand waves, with a root mean square error that is $25 \%$ less.

The safety of pipelines, communication cables and offshore constructions depends on the stability of the seabed. Sand wave migration exposes the pipelines, cables or foundations and thus can

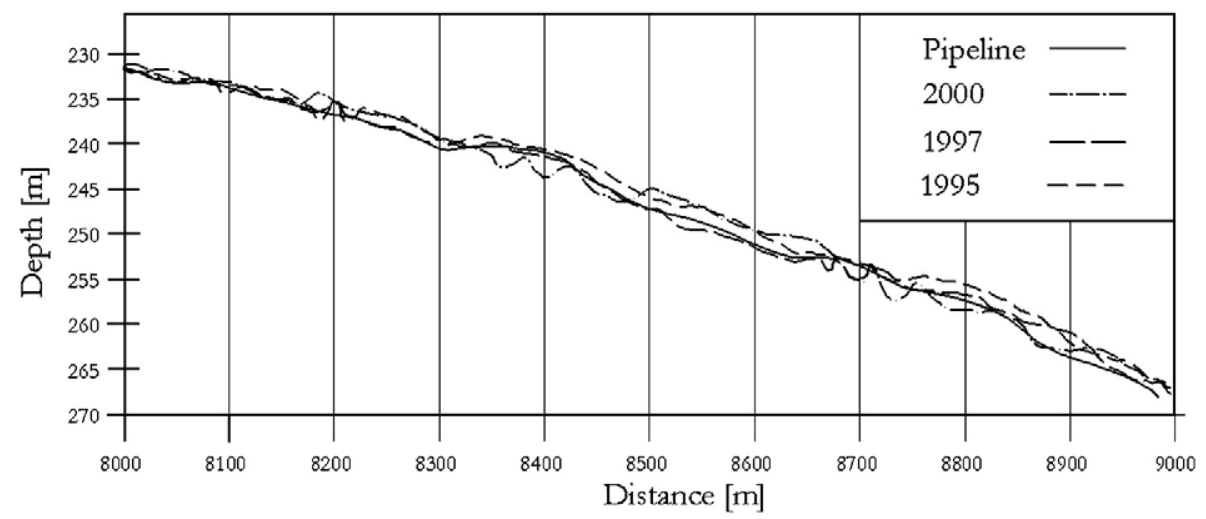

Fig. 2. Surveys of the sea bed profile performed in different years in correspondence of the gas-pipeline between Sicily and the continental part of Italy. Courtesy of SNAMPROGETTI S.p.A. 
result to failure. So far, this has been solved by avoidance, stay away from sand waves or bury the objects deep enough to prevent exposure, or instant repairs by rock dumping. This is an expensive solution, longer lines, deeper foundation, rock dumps and unused areas. Moreover, regular surveys are required to evaluate possible problems before the implementation and to detect any danger after wards. As the migration occurs at slow rates, multiple surveys over several years are necessary to estimate the migration rates (Knaapen, 2005). With sand wave models, these costs can be reduced. The models allow the careful analysis of the sand wave dynamics and the study of the interaction of these bedforms with objects (Morelissen et al., 2003). Van der Veen et al. (2006) show that the models are able to estimate where sand waves may occur using readily available data on flow velocities and grains sizes. Migration models (Németh et al., 2002; Besio et al., 2004) can be used to estimate migration rates using information that can be determined fairly quickly (although weather-induced currents might be a problem). With these models, the need to measure the bathymetry over long periods of time is reduced. Before the models can be trusted in practice, testing of the models is still necessary. This testing is part of ongoing work in the institutes of the authors.

As pointed out by Hulscher (1996), Gerkema (2000) and other authors, the process which gives rise to the formation of sand waves is similar to that originating dunes in rivers (Engelund, 1970) or to that causing the appearance of sea ripples under sea waves (Sleath, 1976; Blondeaux, 1990). In fact, the interaction of the oscillatory tidal current with a bottom perturbation gives rise to a steady streaming in the form of recirculating cells. When the net displacement of the sediment dragged by this steady streaming is directed toward the crests of the bottom waviness, the amplitude of the perturbation grows and bedforms are generated.

To understand and forecast rhythmic morphological features, stability analyses of the flat bottom configuration are commonly used (Dodd et al., 2003). Small periodic perturbations are superposed on the basic morphology. The time development of the perturbations superposed to the basic state is usually studied by assuming that the perturbations are small such to allow linearization of the problem.

Random initial perturbations contain different spatial components which, in a linear approximation, evolve each independently of the other. Hence, a linear analysis suggests that the component characterized by the largest amplification rate will prevail for large times. Linear analysis also predicts a specific wavelength, an orientation and a migration speed of the selected bedforms.

However, predictions of a linear stability analysis are restricted by the small-amplitude assumption. Hence, no information can be gained on the long-term behavior of the actual bottom features. Finite-amplitude effects can be investigated by different approaches, namely weakly-nonlinear stability analyses or numerical integrations of the full system. Weakly-nonlinear stability analyses are based on the assumption that the bedforms, though of finite amplitude, are still small in some sense and their development can be studied by means of a perturbation approach. Such analyses are a well known powerful tool to investigate the time development of perturbations in hydrodynamic stability studies and have also been applied to river and coastal morphodynamics (Colombini et al., 1987; Vittori and Blondeaux, 1990; Schielen et al., 1992) even though, up to now, they have not been used to predict sand wave amplitudes because the linear stability analyses of the sea bed subject to tidal currents do not lead to a finite value of the critical wavelength. In other words, when the tide and sediment characteristics are such to induce the appearance of sand waves, ultra-long bottom waves are the first to become unstable. Only Komarova and Hulscher (2000) have proposed a model to resolve the problem of the excitation of these very long sand waves. The analytical approaches mentioned above are based on the assumption that nonlinear effects are 'somewhat' weak, therefore they usually fail when the system is far from the marginal conditions. When nonlinear effects are strong, only numerical approaches can handle the complex dynamics of the system or alternatively, one may resort to laboratory or field observations. Recently, some attempts to numerically compute the equilibrium configuration of bottom forms have been made and promising results have been obtained, even though many aspects of sand wave dynamics deserve further research.

The main goal of the present paper is to briefly describe the investigations carried out in the framework of the research project "HUMOR" supported by EU. The results obtained by means of theoretical models are summarized in an attempt to provide indications on their use to solve engineering problems.

In the following section we formulate the problem of the appearance and development of bottom forms forced by tidal currents in shallow seas starting from small bottom perturbations. Then, we shortly describe the results of the analyses of the phenomenon available before the starting of the EU research project HUMOR. In Section 3 we give an overview of the research carried out within the HUMOR project and describe the obtained results. Finally, in Section 4 we draw some conclusions and discuss possible developments of the research on the topic.

\section{State of the art on the modeling of sand waves prior to the EU research project "HUMOR"}

The study of sand waves, as all the investigations of morphodynamic phenomena, relies strongly on field observations since the collection and analysis of field data is crucial for the identification and characterization of the bottom forms. However, for the sake of brevity it is not possible to provide an exhaustive review of the papers describing the results of the field surveys of sand waves.

Moreover, since the research groups involved in the HUMOR project focused their attention on the theoretical investigation of sand wave dynamics, we prefer to summarize only previous theoretical studies and we refer the reader interested on field observations to the books of Allen (1984), Stride (1982), to the proceedings of recent conferences on sand waves dynamics (Trentesaux and Garlan, 2000; Hulscher et al., 2004) and to the work of LeBot (Le Bot, 2001; Le Bot and Trentesaux, 2004) and Idier (Idier, 2002; Idier et al., 2002) which provide data on the effects of storms and residual currents on the dynamics of these large-scale bedforms. 
As pointed out in the Introduction, the theoretical investigation of sand wave appearance forced by tide propagation has been mainly carried out by means of linear stability analyses which describe the time development of arbitrary bottom configurations characterized by small amplitudes. Hence, a normal-mode analysis can be applied and the generic component of the perturbation can be considered. Because the horizontal directions are directions of homogeneity, the water depth $h$ can be written in the form

$h(x, y, t)=h_{0}+A(t) / 2 \exp \left[i \alpha_{x} x+i \alpha_{y} y\right]+$ c.c.

where $t$ is time and $x, y, z$ are cartesian coordinates of a fixed reference frame with $x$ and $y$ lying on a horizontal plane and $z$ pointing upward (Blondeaux, 2001). Moreover in Eq. (1) $A(t)$ is the amplitude of the bottom waviness and $\alpha_{x}, \alpha_{y}$ indicate its wavenumbers in the homogeneous directions $x$ and $y$. The time development of perturbations of the sea bottom is controlled by the mass conservation of the sediment. By denoting with $\mathbf{q}(x, y, z, t)$ the volume flux of sediment and by $c(x, y, z, t)$ the volume concentration of solid particles in the flowing mixture, the equation of mass conservation of the solid phase can be written in the form (Seminara, 1998)

$\frac{\partial c}{\partial t}+\nabla \cdot \mathbf{q}=0$

Eq. (2) must be coupled with boundary conditions at the sea bottom and at the free surface. These conditions force a balance between the volume flux of sediment normal to the boundaries and the normal component of the speed of the boundaries themselves multiplied by the local concentration. Taking advantage of the assumption that the flowing mixture is sufficiently dilute for its average concentration to be negligible compared with the concentration of the packed particles and integrating Eq. (2) over the flow depth, a differential equation governing the motion of the bottom profile $z=h(x, y, t)$ can be derived

$\left(1-p_{\mathrm{o}}\right) \frac{\partial h}{\partial t}+\frac{\partial Q_{x}}{\partial x}+\frac{\partial Q_{y}}{\partial y}=0$

where $p_{\mathrm{o}}$ is the void fraction and the total sediment flux $Q_{x}, Q_{y}$ is defined in the form:

$\left(Q_{x}, Q_{y}\right)=\int_{h}^{\eta}\left(q_{x}, q_{y}\right) \mathrm{d} z$

with $z=\eta(x, y, t)$ describing the sea surface. Indeed from Eq. (2) and the Leibniz rule, it follows

$\frac{\partial}{\partial t} \int_{h}^{\eta} c \mathrm{~d} z+\frac{\partial}{\partial x} \int_{h}^{\eta} q_{x} \mathrm{~d} z+\frac{\partial}{\partial y} \int_{h}^{\eta} q_{y} \mathrm{~d} z-\left.c\right|_{\eta} \frac{\partial \eta}{\partial t}+\left.c\right|_{h} \frac{\partial h}{\partial t}-$

$\left.q_{x}\right|_{\eta} \frac{\partial \eta}{\partial x}+\left.q_{x}\right|_{h} \frac{\partial h}{\partial x}-\left.q_{y}\right|_{\eta} \frac{\partial \eta}{\partial y}+\left.q_{y}\right|_{h} \frac{\partial h}{\partial y}+\left.q_{z}\right|_{\eta}-\left.q_{z}\right|_{h}=0$.

Then the first term can be neglected because of the negligible values of the depth-averaged concentration with respect to the concentration of the packed sediment particles. Moreover

$\left.c\right|_{\eta} \frac{\partial \eta}{\partial t}+\left.q_{x}\right|_{\eta} \frac{\partial \eta}{\partial x}+\left.q_{y}\right|_{\eta} \frac{\partial \eta}{\partial y}+\left.q_{z}\right|_{\eta}=0$ because of the boundary condition at the free surface while

$c_{h} \frac{\partial h}{\partial t}+\left.q_{x}\right|_{h} \frac{\partial h}{\partial x}+\left.q_{y}\right|_{h} \frac{\partial h}{\partial y}+\left.q_{z}\right|_{h}=\left(1-p_{0}\right) \frac{\partial h}{\partial t}$

because of the boundary condition at the bottom.

Then a predictor for $Q_{x}$ and $Q_{y}$ is needed. When the shear stress experienced by the interface between the flowing fluid and the resting particles is low, the flow is unable to entrain the particles lying on the bed which then keeps immobile. As the shear stress is increased above some threshold value, which depends on the characteristics of the particles, the sediment starts to move close to the sea bed, rolling, saltating and sliding on the resting particles. This mode of transport, which keeps confined within a thin layer, is called bed load transport. Empirical or semi-empirical relationships are commonly used to quantify $Q_{x}$ and $Q_{y}$ in these circumstances. A second distinct mode of sediment transport is observed as the bed shear stress exceeds a second threshold value. Indeed for large shear stresses, particles are intensely entrained by the flow and move far from the sea bed thus originating the so-called suspended load. Modeling the process of transport in suspension is quite a complex problem. A traditional approach employed in the literature is based on the solution of a convection-diffusion equation for $c$ and on the assumption that $\mathbf{q}=c \mathbf{v}-c w_{\mathbf{s}} \mathbf{k}$ where $\mathbf{v}$ is the fluid velocity vector, $w_{\mathrm{s}}$ indicates the falling velocity of sediment particles and $\mathbf{k}$ is the unit vector in the vertical direction. To close the problem of quantifying the sediment transport in suspension, it is necessary to impose an appropriate boundary condition at the bottom. Again, this is usually achieved by means of empirical relationships.

As described in the following, different models are used to solve the hydrodynamic problem, to evaluate the bottom shear stress and to quantify sediment transport. Usually, the solution procedure leads to an amplitude equation for $A(t)$ in the form

$\frac{\mathrm{d} A(t)}{\mathrm{d} t}=\Gamma(t) A(t)$

where the complex function $\Gamma(t)=\Gamma_{r}(t)+i \Gamma_{i}(t)$ depends on $\alpha_{x}$, $\alpha_{y}$ and on suitable flow and sediment parameters. In the case under investigation, the basic flow is time periodic, due to the presence of the tide and wind waves, and the quantity $\Gamma$ turns out to be a periodic function of time. Then, the solution of Eq. (8) reads

$A(t)=A_{0} \exp \left[\int_{0}^{t} \Gamma(t) \mathrm{d} t\right]$.

Hence, Eqs. (1)-(9) give rise to a bottom configuration described by

$$
\begin{aligned}
h(x, y, t)= & h_{0}+A_{0} / 2 \exp \left[\bar{\Gamma}_{r} t+\int_{0}^{t} \tilde{\Gamma}_{r}(t) \mathrm{d} t\right] \exp \\
& \times\left[i\left(\alpha_{x} x+\alpha_{y} y+\bar{\Gamma}_{i} t+\int_{0}^{t} \tilde{\Gamma}_{i}(t) \mathrm{d} t\right)\right]+\text { c.c. }
\end{aligned}
$$

where $\bar{\Gamma}$ is the time-averaged value of $\Gamma$ and $\widetilde{\Gamma}$ is its periodic part characterized by a zero time-averaged value $\Gamma=\bar{\Gamma}+\widetilde{\Gamma}$. 
Eq. (10) describes a spatial periodic bottom perturbation with a wavelength equal to $2 \pi / \sqrt{\alpha_{x}^{2}+\alpha_{y}^{2}}$. Moreover, the growth/ decay of the perturbation amplitude is controlled by the timeaveraged value $\bar{\Gamma}_{r}$ of $\Gamma_{r}$. The time-averaged value $\bar{\Gamma}_{i}$ of $\Gamma_{i}$ is related to the migration of the bottom forms, the phase speed of which turns out to be $\bar{\Gamma}_{i} / \sqrt{\alpha_{x}^{2}+\alpha_{y}^{2}}$. The periodic parts $\widetilde{\Gamma}_{r}$ and $\widetilde{\Gamma}_{i}$ of $\Gamma$, characterized by zero time-averaged values, describe the oscillations of the bottom profile which take place during the tidal cycle. These oscillations are usually neglected because they are characterized by a very small amplitude. If $\bar{\Gamma}_{r}>0$ $\left(\bar{\Gamma}_{r}<0\right)$, the bottom perturbation grows (decays) exponentially in time. If $\bar{\Gamma}_{r}=0$, the perturbation is neutrally stable, i.e. it propagates like a wave without any growth or decay.

The first model of sand wave appearance, which explicitly tackles the problem of tidal bedforms and takes into account the oscillatory character of the forcing flow was formulated by Hulscher (1996) who described the hydrodynamics by using the shallow water equations. Turbulent stresses were modeled by means of the Boussinesq hypothesis and the introduction of an eddy viscosity, which was assumed to be constant over the water depth. Since, a constant eddy viscosity gives rise to an acceptable velocity profile only when the no-slip condition is replaced by a partial slip condition, the latter was used by Hulscher (1996). Then the hydrodynamic problem was solved by means of a truncation method, which allowed for an analytical solution. Once the water motion was determined, the sediment continuity equation (Eq. (3)) along with a simple sediment transport predictor ( $\mathbf{Q}$ was assumed to be proportional to some power of the effective bottom shear stress corrected by a bottom slope term) led to an amplitude equation in the form of Eq. (8). The mechanism giving rise to sand waves formation was, thus, identified by Hulscher (1996): the interaction of the tidal current with a bottom perturbation gives rise to steady recirculating cells. When the steady streaming close to the bottom is directed from the troughs toward the crests of the bottom waviness, the sediment is dragged in the same direction and the bottom perturbations tend to amplify. This tendency is opposed by gravity, which makes the sediment to move from the crests toward the troughs. Thus, sand wave appearance is controlled by a balance between the above-mentioned effects.

Later on, the predictions obtained on the basis of Hulscher's (1996) model were tested against observations of sand waves and sand banks covering the entire North Sea, since the theoretical model allows for the prediction of sand bank occurrence, too. The model results depend on two parameters, namely $E_{v}$ (the Stokes number) and $\hat{S}$ (a resistance parameter). These parameters are not directly known from measurements. In order to provide estimates for their values, Hulscher and Van de Brink (2001) proposed an analogy between the turbulence model used in Hulscher's (1996) analysis and a more sophisticated approach. The agreement between the theoretical predictions and the field data shows that the model is able to predict fairly well the contours of the area in which sand waves can be expected.

However, the approach employed by Hulscher (1996) is rigorously valid only when the parameter $\hat{r}$, which is the ratio between the amplitude of the horizontal oscillations of the fluid displacement and the water depth (see Eq. (14)), is not large. In the field $\hat{r}$ is typically of $O\left(10^{2}\right)$ and Gerkema (2000) solved the problem by using an asymptotic approach which holds for large values of both $\hat{r}$ and $s$ ( $s$ being the resistance parameter appearing in the partial slip condition at the sea bed, see Eq. (14)), thus finding more accurate quantitative results, even though no qualitative difference is present.

Both the analysis of Hulscher (1996) and that of Gerkema (2000) show that close to the critical conditions the bottom perturbations that become unstable are characterized by ultra-long wavelengths. A height- and flow-dependent model for the eddy viscosity has been adopted by Komarova and Hulscher (2000) to resolve the problem of the excitation of these very long sand waves. In the model used by Komarova and Hulscher (2000), the eddy viscosity changes in time and along the horizontal direction for a term proportional to the amplitude of the bottom perturbation. With this schematization of turbulence structure, the most unstable modes are characterized by wavelengths which are similar to the sand wave spacing observed in the field. Moreover, when the local hydrodynamic and morphodynamic conditions are such to give rise to sand waves, the first component of the bottom perturbations which starts to grow is characterized by a finite wavelength.

The results of Komarova and Hulscher (2000) suggested that further refinements of turbulence modeling are necessary to obtain accurate quantitative predictions of bedforms characteristics. In Idier et al. (2004), the generation of bedforms having a wavelength of the order of $300 \mathrm{~m}$, similar to the sand wave wavelength observed in the field, has been reproduced with parameters directly estimated from physical parameters (water depth, grain roughness, current velocity, repose angle of sediment), using a model (the numerical model Telemac) based on 3D hydrodynamic equations with a mixing length turbulence model, taking into account bedload and gravity driven sediment flux.

\section{The research carried out in the framework of the "HUMOR Project"}

In the framework of the research project HUMOR, supported by the European Union, the processes leading to the formation of sand waves have been investigated thoroughly. The obtained results are based on models which differ because of the different assumptions introduced to solve the hydrodynamics and because of the different empirical relationships used to quantify the transport of the sediment.

When the flow generated by a tidal wave propagating over a cohesionless bottom is studied, the hydrodynamic problem is posed by the continuity and the Reynolds-averaged NavierStokes equations which read

$$
\nabla \cdot \mathbf{v}=0
$$

$$
\frac{\partial \mathbf{v}}{\partial t}+(\mathbf{v} \cdot \nabla) \mathbf{v}=-\frac{1}{\rho} \nabla p+\nabla \cdot\left(2 v_{\mathrm{T}} \mathbf{D}\right)
$$

where $\mathbf{D}$ is the strain rate tensor, $p$ is the pressure and $v_{\mathrm{T}}$ is the eddy kinematic viscosity which is introduced to model the Reynolds stresses. 
In Németh et al. (2002), Besio et al. (2003), Besio et al. (2004), a constant value of the eddy viscosity is considered and the viscous term in the momentum equation becomes $v_{\mathrm{T}} \nabla^{2} \mathbf{v}$. As already pointed out, a constant value of the eddy viscosity provides an acceptable velocity profile only when the no-slip condition at the bottom is replaced by a partial slip condition. When a unidirectional tidal current is considered, the latter reads

$\frac{\partial u_{\|}}{\partial n}=\tilde{s} u_{\|}$

where $\partial / \partial n$ denotes the derivative in the direction normal to the bottom, $u_{\|}$indicates the along-slope velocity component and $\widetilde{s}$ a resistance parameter, the value of which should be properly chosen.

In order to solve the mathematical problem, it is convenient to introduce dimensionless variables. The mean water depth $h_{0}$ is used as length scale, while the amplitude $U_{0}$ and the inverse of the frequency $\omega^{-1}$ of the depth-averaged velocity oscillations induced by the tide are used as velocity and time scales, respectively. The dimensionless hydrodynamic problem is characterized by the following dimensionless parameters

$\hat{r}=\frac{U_{0}}{h_{0} \omega}, \quad \delta=\sqrt{\frac{v_{\mathrm{T}} / \omega}{h_{0}}}, \quad s=\tilde{s} h_{0}$.

The velocity $U_{0}$ is of order $1 \mathrm{~m} / \mathrm{s}$ and $\omega$ is equal to $1.5 \times 10^{-4} \mathrm{~s}^{-1}$ for a semi-diurnal tide and to $0.7 \times 10^{-4} \mathrm{~s}^{-1}$ for a diurnal tide. Finally, $h_{0}$ is of order $10 \mathrm{~m}$. Therefore, $\hat{r}$ attains values of order $10^{2}-10^{3}$. Since tidal currents are characterized by a time scale much larger than that of the turbulent eddies, an estimate of the eddy viscosity $v_{\mathrm{T}}$ and of the resistance parameter $\widetilde{s}$ can be obtained from the knowledge of turbulent structure and eddy viscosity in steady currents. In particular by equating $v_{\mathrm{T}}$ to the depth-averaged value of the empirical relationships proposed to describe the vertical variations of the kinematic eddy viscosity and by forcing the shear stress acting on the bed to be equal to $\rho\left(U_{0} / C\right)^{2}$, where $C$ is a friction coefficient which depends on the bottom roughness, reliable values of $v_{\mathrm{T}}$ and $\widetilde{s}$ are obtained. It can be concluded that $v_{\mathrm{T}}$ ranges around $\left(10^{-2}-10^{-1}\right) \mathrm{m}^{2} / \mathrm{s}$ and $s$ around $\left(10^{-2}-10^{-1}\right) \mathrm{m}^{-1}$. It follows that typical values of both $\delta$ and $s$ are of order 1 . Other authors could prefer the use of the stroke of the horizontal tide $U_{0} / \omega$ or the inertial length $C^{2} h_{0}$ as length scale instead of $h_{0}$. These alternative choices have no effect on the solution procedure and on the results as long as finite values of the parameters $\hat{r}$ and $\delta$ are considered. Since no assumption is introduced on the values taken by $\hat{r}$ and $\delta$, the local water depth has been preferred as length scale since it is easier to appreciate the wavelength of the bottom forms from the knowledge of the growth rate as function of dimensionless wave number of the bottom perturbations (see Figs. 4, 6, and 7).

\subsection{The hydrodynamics: improvements of the solution procedure}

To improve the analyses that are summarized in Section 2 and are strictly valid either for relatively small values of $\hat{r}$ or for large values of both $\hat{r}$ and $s$, Besio et al. (2003) solved the hydrodynamic problem by means of a procedure similar to that employed by Vittori (1989) in a different context, and is valid for arbitrary values of $\hat{r}, \delta$ and $s$. A Fourier series in time is used to compute the stream-function associated with the flow perturbations induced by the interaction of the tidal current with the bottom waviness. The approach leads to a set of coupled ordinary differential equations which describes the vertical variation of the amplitude of the Fourier components and has been solved with a "shooting procedure". To support the obtained results, Besio et al. (2003) solved the problem also for small and large values of the parameter $\hat{r}$ using perturbation approaches and successfully compared the results with those obtained by means of the general approach. Once the streamfunction associated with the bottom perturbation is computed, the temporal development of the amplitude of the generic component of the perturbation can be easily evaluated from the sediment continuity equation. This leads to an equation in the form of Eq. (8), where the function $\Gamma(t)$ depends on the sediment transport predictor used in the model. Besio et al. (2003) considered only bed load transport, which for field conditions usually dominates the suspended load, and used the relationship proposed by Meyer-Peter and Müller (1948) to quantify it, adding a term to take bed slope effects into account.

The performances of the model can be evaluated by looking at Figs. 3 and 4. Fig. 4 shows the amplification rate $\bar{\Gamma}_{r}$ for $\hat{\mu}=112.5$, $s=1.02, \hat{r}=79$ and $\hat{\Psi}_{\mathrm{d}}=0.0045$, values of the parameters which are chosen to reproduce the site in the North Sea shown in Fig. 3 where sand waves have been observed. The dimensionless parameter $\hat{\Psi}_{\mathrm{d}}$, called the "mobility number" of the sediment, is related to the particle characteristics and is defined as

$\hat{\Psi}_{\mathrm{d}} \equiv \frac{\left(h_{0} \omega\right)^{2}}{\left(\rho_{\mathrm{s}} / \rho-1\right) g d}$

while $\hat{\mu}$ is the viscous parameter

$\hat{\mu}=\frac{U_{0} h_{0}}{v_{\mathrm{T}}}=\frac{\hat{r}}{\delta^{2}}$.

Since the turbulence models usually assume that $v_{\mathrm{T}}$ is proportional to $U_{0}$, the parameters $\hat{\Psi}_{\mathrm{d}}$ and $\hat{\mu}$ are defined in such a way that the strength of the tidal current $U_{0}$ only appears in the parameter $\hat{r}$. However, because both $\hat{\Psi}_{\mathrm{d}}$ and $\hat{\mu}$ are assumed to have finite values, the introduction of other parameters (e.g. the mobility number $\left.U_{0} /\left[\left(\rho_{\mathrm{s}} / \rho-1\right) g d\right]\right)$ would have no effect on the solution procedure and on the results.

If it is assumed that sand waves are generated by the growth of the bottom perturbations characterized by the largest amplification rate and it is taken into account that $\bar{\Gamma}_{r}$ is maximum for $\alpha_{x}=0.4$ and the local water depth is about $21 \mathrm{~m}$, the model predicts the formation of sand waves characterized by a wavelength equal to about $315 \mathrm{~m}$, a somewhat larger value than that observed in the field ranging between $165 \mathrm{~m}$ and $255 \mathrm{~m}$. Therefore, the comparison between the model finding and the field data shows that the theoretical model qualitatively describes the phenomenon even though further refinements of some aspects of the model (e.g. the turbulence closure approach, 


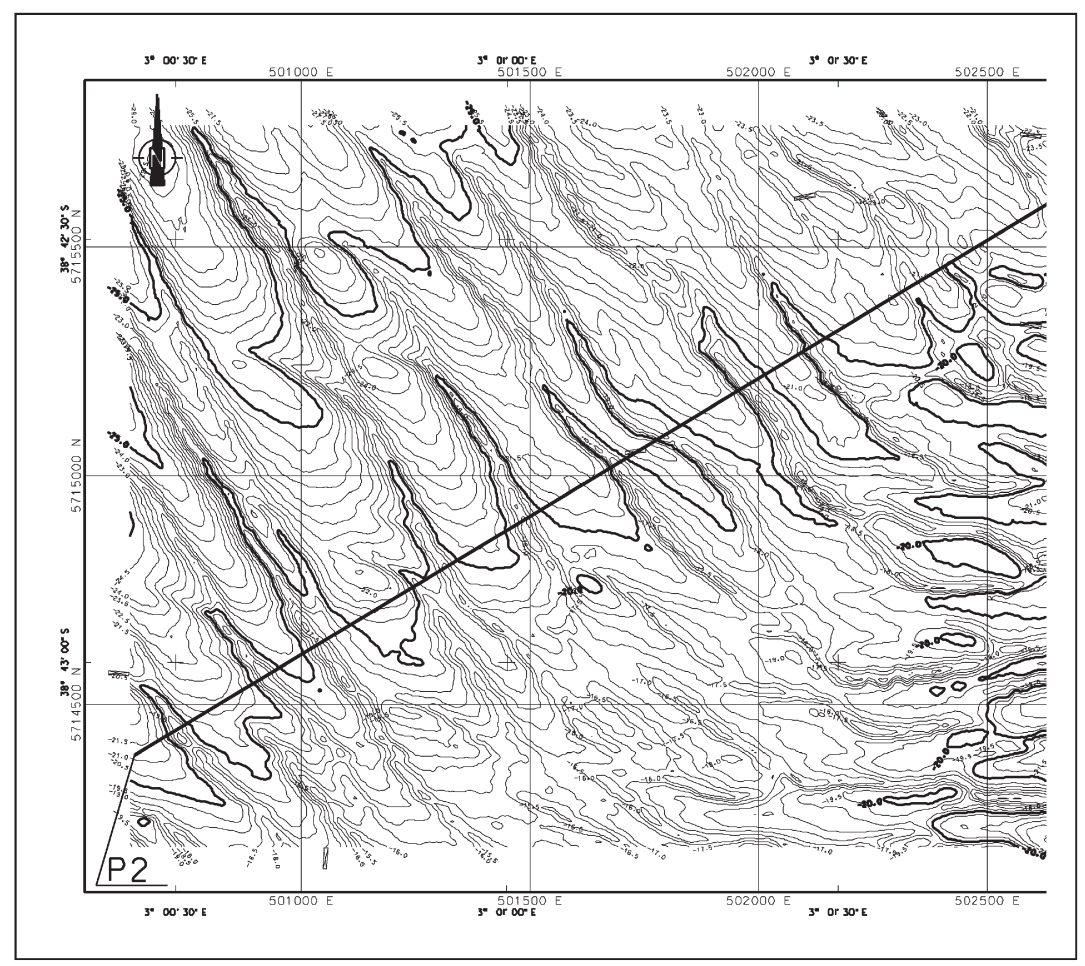

PROF ILE 2

ORIENTATION 59 DEG. NORTH

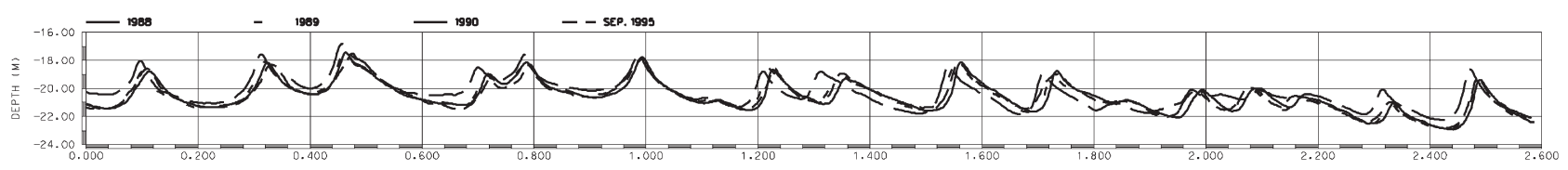

Fig. 3. Sand waves data. Top: contour map of the seabed at $51^{\circ} 35^{\prime} \mathrm{N}$ and $3^{\circ} 2^{\prime} \mathrm{E}$ (SW1 site) with reference transect P2. Bottom: seabed profile along transect P2 (adapted from Besio et al., 2006).

the sediment transport predictor, the description of sea waves effects, ...) are required to obtain a good quantitative agreement between the theoretical predictions and the results of the field surveys.

\subsection{The hydrodynamics: the effects of the residual current}

In Besio et al. (2003), like in previous studies of sand waves, a unidirectional oscillatory and symmetrical tidal current is considered and the bottom perturbations do not migrate because the flow at the generic time $t$ is the mirror image of that at time $t+T / 2$ ( $T$ is the period of the tide). Therefore, the models provide zero values of the imaginary part of $\bar{\Gamma}$ and the migration speed turns out to vanish, too. However, as mentioned in the Introduction, there are many human activities for which sand wave migration and the prediction of the migration speed of the bedforms for field conditions are very important. Sand wave migration can be explained only when the tidal symmetry is disrupted by the presence of a residual current and/or the simultaneous presence of many tide constituents.

Németh et al. (2002) consider two different mechanisms able to generate a net displacement of sand waves after a tidal cycle. The former is associated to the presence of a steady residual current and the latter is due to the presence of surface wind stresses. The model is similar to that used by Hulscher (1996) and is based on the two-dimensional vertical shallow water equations. In other words, since sand waves are a few hundreds

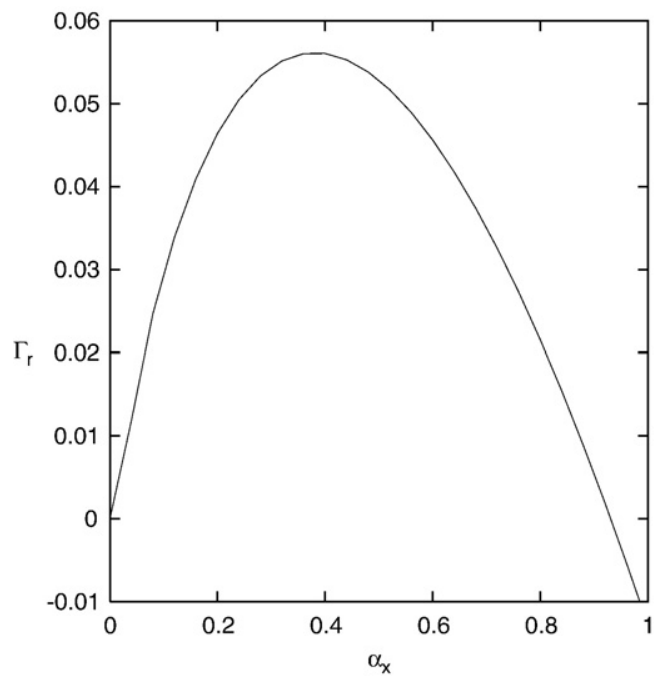

Fig. 4. Dimensionless growth rate $\bar{\Gamma}_{r}$ plotted versus the dimensionless wavenumber $\alpha_{x}$ of the bottom perturbation. Model parameters are: $\hat{\mu}=112.5$, $s=1.02, \hat{r}=79, \hat{\Psi}_{\mathrm{d}}=0.0045, \gamma=0.05$ and $\theta_{\mathrm{c}}=0.047$. 
of meters long and the water depth is of order $10 \mathrm{~m}$, because of the small values assumed by the ratio $h_{0} / L$ ( $L$ equal to the horizontal length scale of the problem), the horizontal diffusion term in Eq. (12) can be neglected and the vertical component of the momentum equation forces a hydrostatic distribution of the pressure. Finally, the vertical velocity component, which is assumed to be much smaller than the horizontal one, is provided by the continuity equation. In the model of Németh et al. (2002), the eddy viscosity is assumed to be constant and a partial slip condition is imposed at the bottom. The flow perturbation is determined by considering its steady and synchronous components. Indeed, this truncated solution contains the physical processes which give rise to sand wave migration. The sediment transport rate is assumed to be proportional to the 3/2-power of the bottom shear stress and a correction is introduced to account for the bed slope effects. Fig. 5 shows both the real and imaginary parts of $\bar{\Gamma}$. When the residual current is absent and the wind stress vanishes, $\bar{\Gamma}_{i}$ turns out to be zero and the bottom perturbation does not propagate. However, when the tidal symmetry is broken by the presence of either a steady current or wind stresses, $\bar{\Gamma}_{i}$ turns out to be negative and sand waves do migrate in the direction of the residual current with a migration rate of several meters per year for typical North Sea conditions. The morphological time scale is about 6 years, a value which is in line with Knaapen and Hulscher (2002) who investigated field data sets and found a time scale of 8 years.

\subsection{The hydrodynamics: the effects of many tide constituents}

In the literature (see a.o. Németh et al., 2002), it is usually reported that sand waves generated by tidal currents migrate

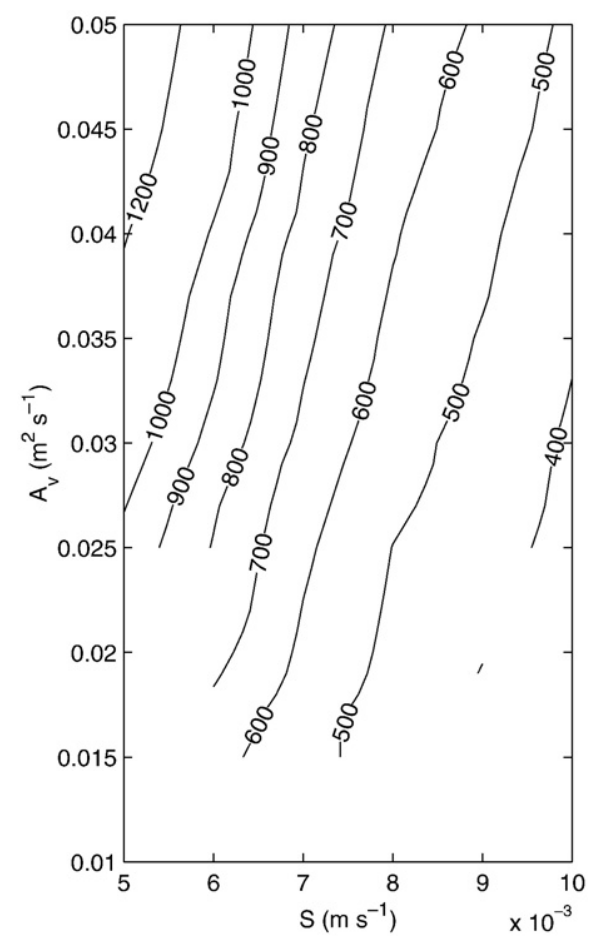

downstream, i.e. in the direction of the residual steady current. However, a few examples of upstream-migrating sand waves exist (Besio et al., 2004). A simple mechanism exists which can give rise to an upstream migration. Indeed, the symmetry of the recirculating cells is also broken when the flow is forced by the simultaneous presence of the M2 and M4 tide constituents which generate a flow characterized by a vanishing timeaveraged but with a preferred direction. The theoretical investigation of sand wave migration induced by the superposition of different tide constituents has been carried out by Besio et al. (2004). The analysis closely follows that of Besio et al. (2003); the inclusion of the residual current and various harmonic components of the tidal wave in the description of the phenomenon is the main novelty of the work of Besio et al. (2004).

Figs. 6 and 7 show both the real and imaginary parts of $\bar{\Gamma}$ for values of the parameters chosen to reproduce a particular site in the North Sea. In Fig. 6 the results have been obtained considering a forcing due to the superposition of the M2 and Z0 tide constituents, while in Fig. 7 the presence of the M4 constituent is accounted for. From the results plotted in Fig. 6, it appears that sand waves migrate in the direction of the residual current. Indeed, a negative value of $\bar{\Gamma}_{\text {i gives rise to a migration }}$ of the sand waves in the positive $x$-direction which is the direction of the residual current. However, Fig. 7 shows that the M4 tide constituent, with an appropriate phase shift $\phi$, gives rise to a positive value of $\bar{\Gamma}_{i}$ and to a migration of sand waves in the direction opposite to that of the residual current. A quantitative comparison of the theoretical results with field data shows that the theory provides fair predictions. In particular, the obtained results show that sand waves migrate

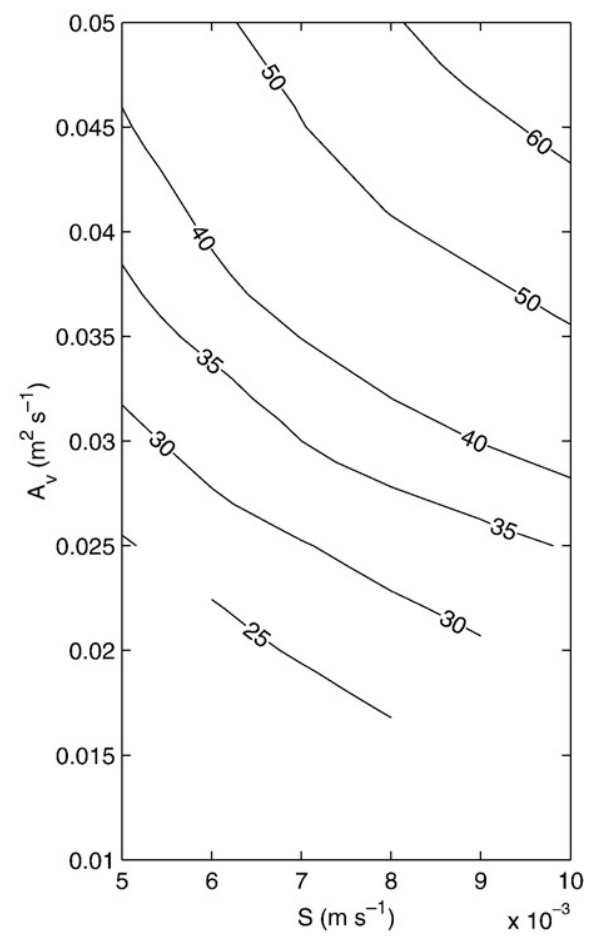

Fig. 5. Properties of the fastest-growing mode as a function of the resistance parameter and for different values of the eddy viscosity. Left panel: wavelength (m). Right panel: migration rate $\left(\mathrm{m} \mathrm{yr}^{-1}\right)$. A typical North Sea location has a value for the resistance parameter of about $0.008 \mathrm{~m} \mathrm{~s}^{-1}$ and an eddy viscosity of $0.01 \mathrm{~m}^{2} \mathrm{~s}^{-1}$. 
(a)

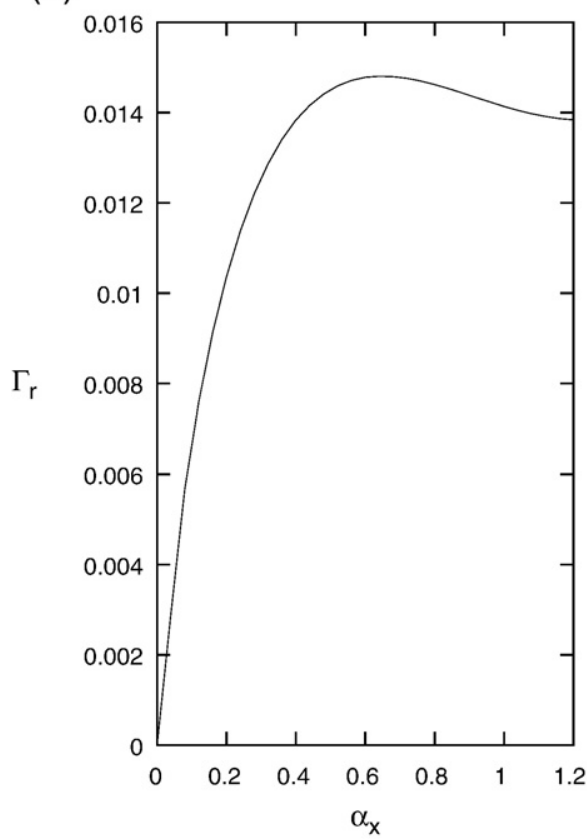

(b)

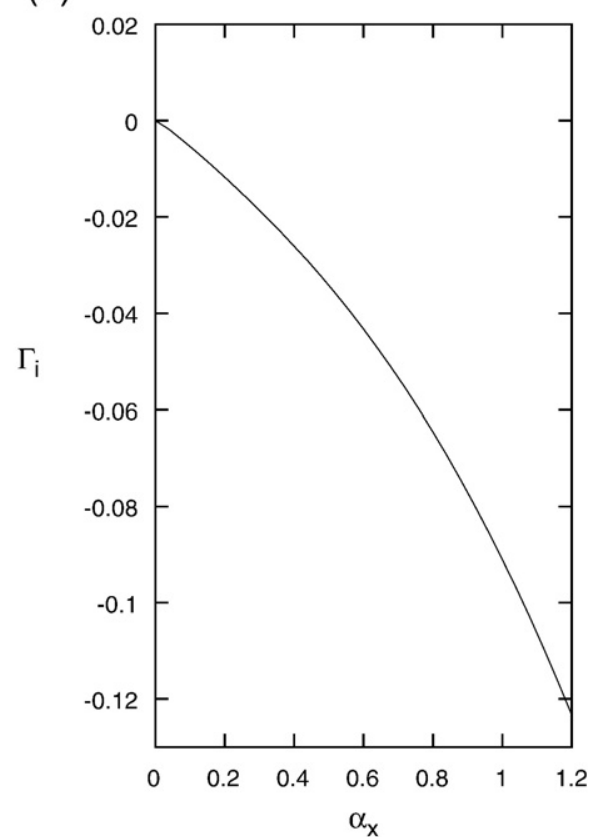

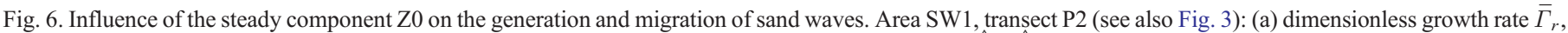
(b) dimensionless migration speed $\bar{\Gamma}_{i}$. Model parameters are: $\hat{r}=187, \gamma=0.23, \mu=1.73, s=0.84$ and $\hat{U}_{0_{\mathrm{m}}} / \hat{U}_{1_{\mathrm{m}}}=0.043$.

downstream or upstream depending on the strength and relative phase of the different tide constituents.

\subsection{The hydro- and morphodynamics: a fully $3 D$ model including suspended load and sediment transport due to the wind waves}

A more refined model describing the generation and evolution of tidal sand waves from bottom perturbations of a flat sea bed subject to the action of tidal currents has been

(a)

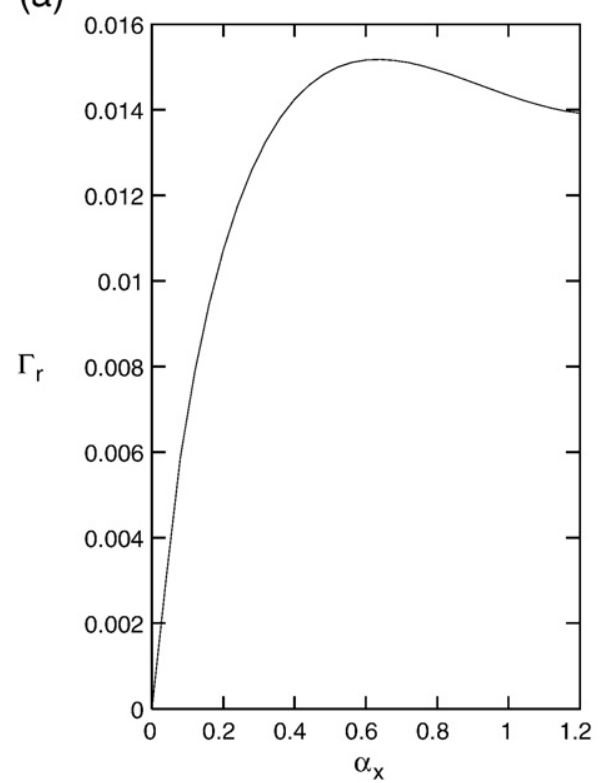

proposed by Besio et al. (2006). A horizontally twodimensional basic flow forced by a tidal wave is considered and Coriolis effects are taken into account since they affect tide propagation. The basic flow is completely resolved also in the vertical direction from the free surface down to the sea bed where the no-slip condition is forced. Besio et al. (2006) not only describe the sediment transport due to the tidal flow but also the contribution which arises because of the presence of wind waves which often coexist and have a large influence on

(b)

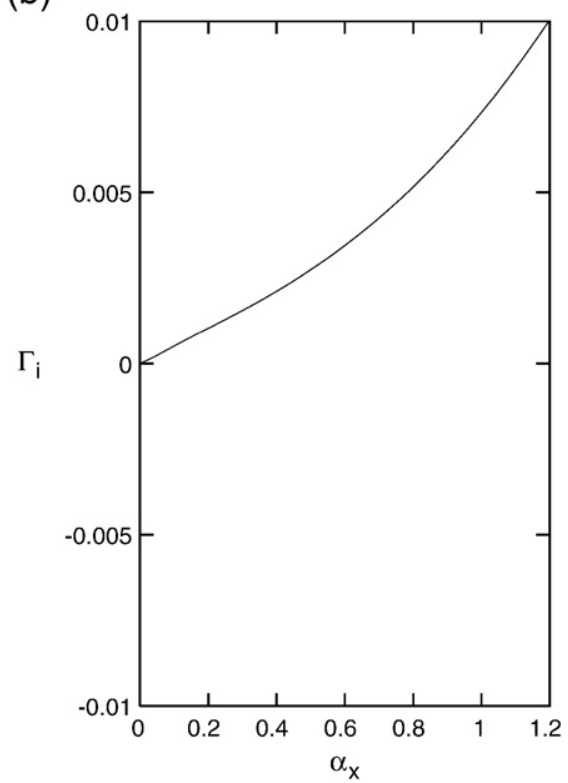

Fig. 7. Generation and migration of sand waves in the area SW1 caused by Z0, M2 and M4. Transect P2: (a) dimensionless growth rate $\bar{\Gamma}_{r}$, (b) dimensionless migration speed $\bar{\Gamma}_{i}$. Model parameters are: $\hat{r}=187, \gamma=0.23, \mu=1.73, s=0.84, \hat{U}_{0_{\mathrm{m}}} / \hat{U}_{1_{\mathrm{m}}}=0.043, \hat{U}_{2_{\mathrm{m}}} / \hat{U}_{1_{\mathrm{m}}}=0.145$ and $\phi=60.7^{\circ}$. 
the growth of bottom forms. For example Langhorne (1982) reports a significant decrease of the sand wave height $(30 \%$ reduction) due to a storm. Also residual (steady) currents are taken into account because their presence is essential in explaining sand wave migration. Sediment is supposed to move both as bed load and suspended load since field surveys show that large amounts of sediment are set into suspension by the stirring action of wind waves and then transported by tidal currents. Moreover, the effects of bottom slope on sediment transport are quantified by an accurate relationship.

The results obtained by Besio et al. (2006) agree well with field observations. Indeed the strength of the tidal currents able to trigger sand waves is well predicted as well as the main characteristics of the bottom forms (wavelength, orientation). The model can also predict the migration speed of sand waves, which is induced by residual currents or by the interaction of different tidal constituents.

\subsection{Data assimilation: amplitude evolution model}

The analyses summarized so far support the idea that sand waves in tide-dominated coastal areas arise because of an inherent instability of the flat bottom configuration subject to tidal currents.

The consequence of sand waves being free instabilities is that they tend to recover after dredging. This phenomenon has been observed by Katoh et al. (1998) who monitored the sea bed in the Bisanseto Sea after a field of sand waves was topped off to keep the navigation channel sufficiently deep. In particular, Katoh et al. (1998) showed that sand waves regenerate in several-years time. The costs of repeated dredging are high and the responsible authorities want to minimize these costs. Therefore, it is crucial to know the rate at which the sand waves regain their original shape. However, the linear analyses, previously described, neglect nonlinear effects. Hence, they can explain the mechanism triggering the growth of the bottom forms forced by the propagation of a tidal wave and can predict some of their characteristics (i.e. wavelengths, migration speed and initial growth rates), but they can predict neither the equilibrium attained by the bottom configuration nor the time which is required to attain this equilibrium shape.

Close to the critical conditions, the time development of the amplitude of the bottom perturbations including weaklynonlinear effects could be predicted using the Landau and Ginzburg amplitude equation, obtained by studying the selfinteraction of the most unstable bottom perturbation of small but finite amplitude, when the parameters are close to their critical values. However, the analysis is tedious and lengthy. Hence, Knaapen and Hulscher (2002) choose a different approach to get an amplitude equation. They postulated that the system is close to the critical conditions and determined the coefficients of the amplitude equation and the initial amplitude of the bottom waviness by using a genetic algorithm which fits the parameters of the model to the field data.

Because of the nonlinearity of the model, gradient search algorithms are not very effective (Fluodas and Pardalos, 1996). Therefore, Knaapen and Hulscher (2002) used a global optimization routine. The algorithm is based on the evolution theory. The obtained results show that the proposed model gives a good representation of the process of sand wave growth in time. This makes it a useful tool for coastal management. Once the model has been tuned, it can estimate the time development of the amplitude of sand waves without expensive monitoring activities. Fig. 8 shows a comparison between the time development predicted by Knaapen and Hulscher's (2002) model and the field data collected by Katoh et al. (1998). The good agreement between the theoretical results and the field surveys provides support to Knaapen and Hulscher's (2002) analysis.

\subsection{Data assimilation: amplitude evolution and migration}

In the model developed by Knaapen and Hulscher (2002), the coefficients appearing in the nonlinear amplitude equation are assumed to be real. Hence, the sand wave amplitude attains a constant value after about a decade, but the bedforms do not migrate. As they were interested in the water depth only this was no limitation to them. Morelissen et al. (2003) applied the same approach to the safety of pipelines. For this application, they chose the coefficients to be complex, i.e. have an imaginary part. This introduces migration in the model. Since migrating sand waves are asymmetric, Morelissen et al. (2003) also introduced higher harmonics to the first order model of Knaapen and Hulscher (2002). With these adaptations, a migrating bottom profile can be characterized by few parameters. The values of these parameters are determined based on profiles observed in the field using a global optimization technique. The analysis has been applied to both active and decommissioned offshore pipelines by coupling their sand wave model to a model simulating selflowering and self-burying of pipelines (PIPESIN — http://www. alkyon.nl/Tools/Pipesin.htm; Chen and Bijker, 2001). When a pipeline is exposed on the seabed, it will influence the water flow like any other object. Close to the pipeline, this leads to increased flow velocities causing scour. The scouring will locally lower the seabed. If the flexibility of the pipeline is sufficient, the pipeline will be lowered as well. This restores the undisturbed flow, and

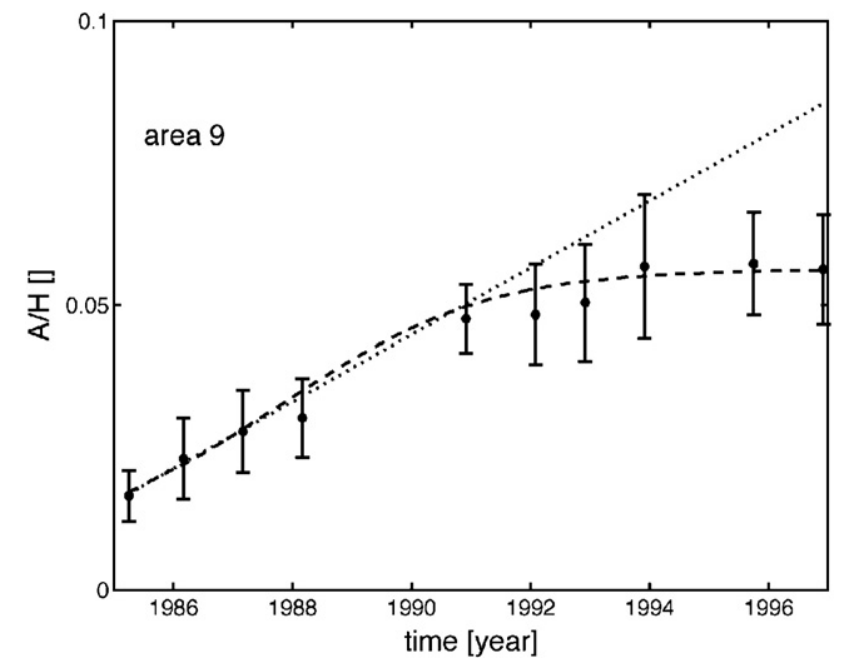

Fig. 8. Prediction of the sand wave growth evaluated using the model (dashed line) and a linear trend analysis (dotted line), plotted against field measurements. 
the scour hole will fill, burying the pipeline again. This combination of sand wave model and self-burying model can evaluate whether free spans will develop due to sand wave migration or the self-lowering mechanism can compensate for the bed level changes due to migration. For a fairly small pipeline, the analysis showed that the latter was true, even in case of dredging of the top $25 \%$ of the sand wave crests causing exposure of the pipelines over tens of meters (Fig. 9). The regeneration of the sand waves, which occurs in about 7 years according to Knaapen and Hulscher (2002), together with the self-burying due to scour prevents the occurrence of free spans. This shows that dredging does not necessarily lead to large exposure of the pipelines, which would increase the risk of buckling or breaking of the pipeline. If this would hold for more pipelines, this would allow for marine aggregate extraction in some of the pipeline areas, reducing the pressure on ecologically more sensitive areas of shallow seas. However, these are only preliminary results on a small pipeline, and have to be tested on more and larger pipelines.

\subsection{Nonlinear analyses: finite amplitude sand waves}

To investigate the intermediate-term behavior of sand waves having finite amplitudes, a numerical simulation model (2DV) is developed in Németh (2003). This model allows the evolutionary processes of sand waves after their initial evolution to be investigated.

The model is based on the 2DV shallow water equations, with a free water surface and a general bed load formula. The water movement is coupled to the sediment transport equation by a seabed evolution equation. The spatial discretisation is performed by a spectral method based on Chebyshev polynomials. A fully implicit method is chosen for the discretisation in time. The model is validated by comparing the results for small-amplitude sand waves with the theoretical findings of a linear stability analysis (Németh et al., 2002). The results show that the numerical model is able to reproduce the initial evolution of sand waves, as it was found in the linear stability analysis (Németh, 2003).

Next, the simulation model was used to investigate the behavior of offshore sand waves for finite values of their amplitude (Németh and Hulscher, 2003 and Németh et al., 2007). A unidirectional steady current and a unidirectional block current simulating tidal motion were investigated. Initially, the sand waves develop exponentially, as follows from the linear stability analysis. Next, the growth rate diminishes, resulting in the stabilization of the sand waves (see Fig. 10). The sand waves reach a maximum height of about $10-30 \%$ of the average water depth in a matter of decades. The mechanism causing sand waves to saturate is based on the increased importance, for larger amplitudes, of the principle that sediment is transported easier downhill than uphill. This process counteracts the shear stress at the seabed transporting sediment upward toward the crest.

For a unidirectional steady flow in an offshore setting, we find sand waves with wavelengths in the order of hundreds of meters, based on linear theory, when the resistance at the seabed is relatively large. These sand waves migrate and become asymmetrical in the horizontal direction, as it is found for dunes in rivers. The migration rate of the sand waves decreases slightly during their evolution. For a unidirectional block current slightly elongated troughs and sharp crests are found. A sensitivity analysis showed that the slope effects on the sediment transport play an important role. Furthermore, the magnitude of the resistance at the seabed and the eddy viscosity influence both the timescale and the height of the fullydeveloped sand waves. The orders of magnitude of the time and spatial scales coincide with observations made in the southern bight of the North Sea and Spain (Németh et al., 2007) and Japan (see also Knaapen and Hulscher, 2002).

Using this simulation model, the recovery of dredged sand waves is investigated in Németh and Hulscher (2003). Sand waves are able to recover after they are dredged (see also Knaapen and Hulscher, 2002). The timescale and resulting maximum height depend on the amount of sand dredged and where the sand is dumped. The interested reader can find more details on the nonlinear model in Németh et al. (2006).

\subsection{Linear evolution of sand wave packets}

The existing models of sand wave formation, described in Sections 3.1-3.4, typically describe the dynamics of wavy patterns of infinite spatial extent. Recently, Roos et al. (2005) have investigated how a local topographic disturbance of a flat seabed behaves subject to the linear instability mechanism associated with sand wave formation. The time development of such a disturbance can be expressed in terms of a Fourier

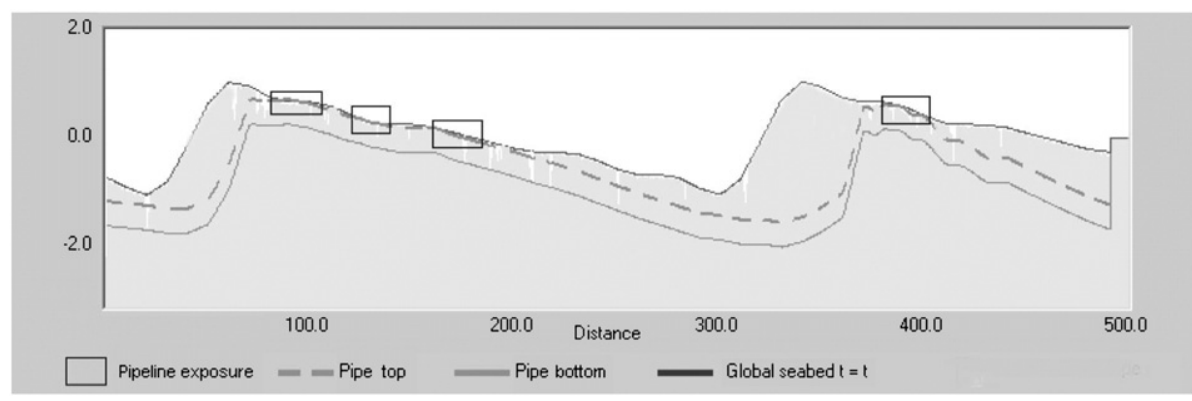

Fig. 9. Predicted pipe and seabed levels in 2006, directly after dredging. The dashed line and the solid line indicate the top and bottom of the pipeline, while the squares indicate areas of pipeline exposure. After Morelissen et al. (2003). 

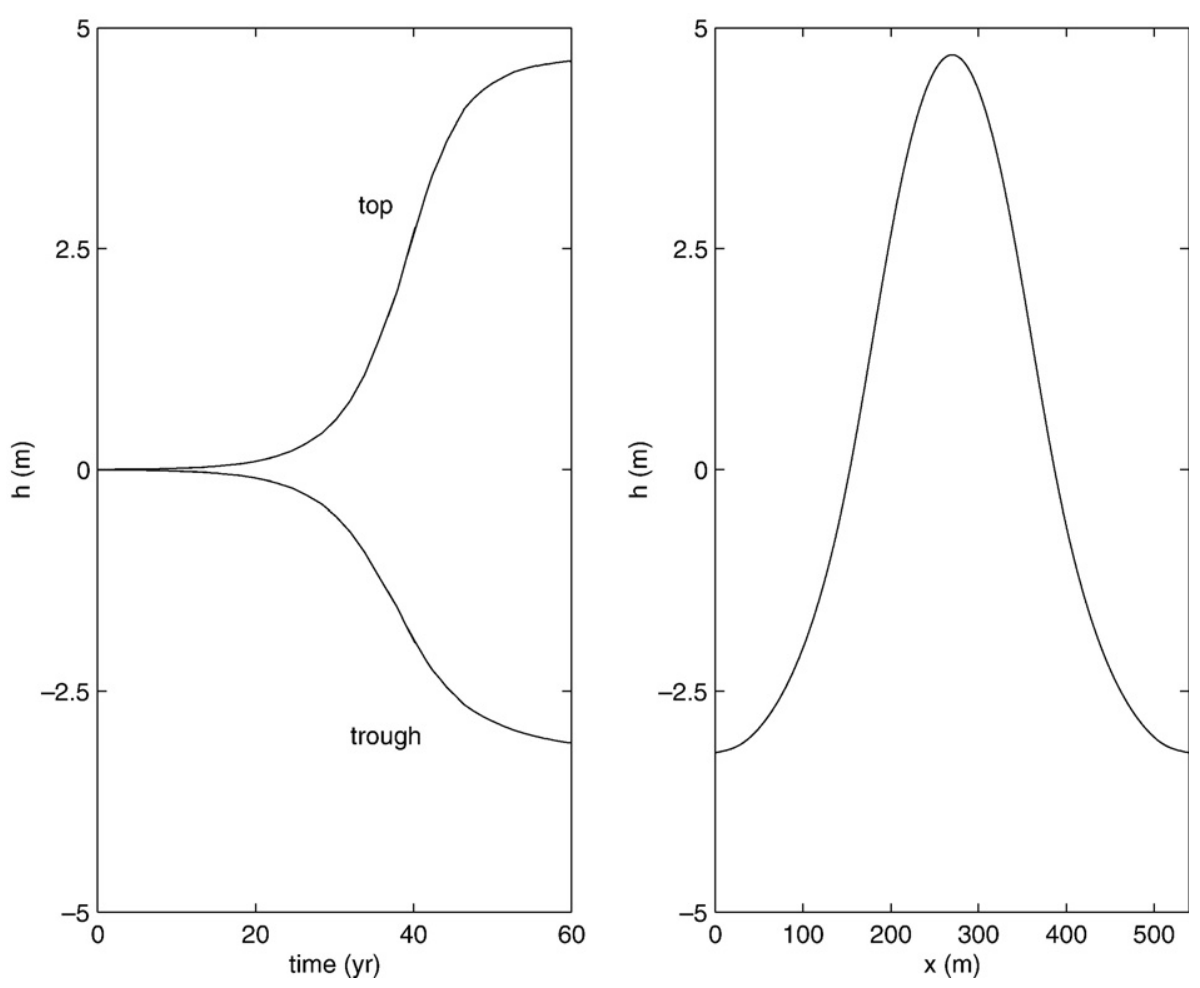

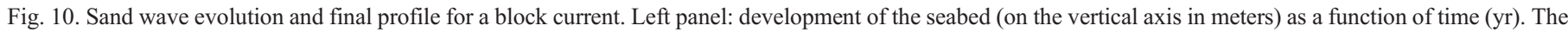

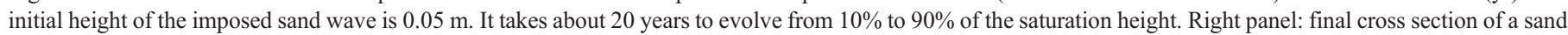
wave (which is part of a sand wave pattern).

integral containing the spectrum $\widetilde{h}\left(\alpha_{x}, \alpha_{y}\right)$ of the local instantaneous bathymetry:

$$
\begin{aligned}
h(x, y, \tau) & =h_{0}+\int_{-\infty}^{\infty} \int_{-\infty}^{\infty} \tilde{h}\left(\alpha_{x}, \alpha_{y}, t\right) e^{i\left(\alpha_{x} x+\alpha_{y} y\right)} \mathrm{d} \alpha_{x} \mathrm{~d} \alpha_{y} \\
& =h_{0}+\int_{-\infty}^{\infty} \int_{-\infty}^{\infty} \tilde{h}_{\text {init }}\left(\alpha_{x}, \alpha_{y}\right) e^{\bar{\Gamma}\left(\alpha_{x}, \alpha_{y}\right) t} e^{i\left(\alpha_{x} x+\alpha_{y} y\right)} d \alpha_{x} d \alpha_{y}+\text { c.c. }
\end{aligned}
$$

in Eq. (17), $h_{0}$ is the mean water depth, $\widetilde{h}_{\text {init }}\left(\alpha_{x}, \alpha_{y}\right)$ is the Fourier spectrum of the initial bottom perturbation, in which every possibly wave vector $\left(\alpha_{x}, \alpha_{y}\right)$ is represented and $\bar{\Gamma}\left(\alpha_{x}\right.$, $\left.\alpha_{y}\right)=\bar{\Gamma}_{r}+i \bar{\Gamma}_{i}$ is the tide-averaged complex growth rate taken from any existing process-based sand wave formation model (see Eqs. (1) and (13)).

Roos et al. (2005) have proposed an analytical approach to approximate the solution of this integral. They have considered a local, three-dimensional perturbation with a Gaussian shape, and they have approximated the dispersion relationship $\bar{\Gamma}\left(\alpha_{x}, \alpha_{y}\right)$ quadratically around the fastest-growing mode $\left(\alpha_{x, \mathrm{fgm}}, \alpha_{y, \mathrm{fgm}}\right)$ (i.e., the mode for which the growth rate $\bar{\Gamma}_{r}$ attains its maximum). The proposed method is quick, insightful and performs well.

\section{(a) envelope}
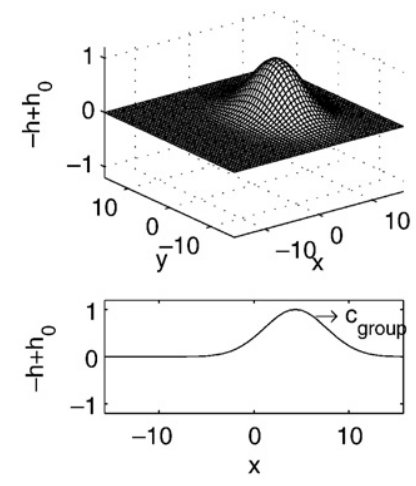

(b) pattern
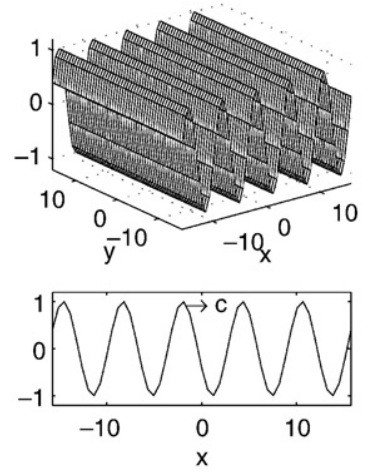

(c) envelope $\times$ pattern
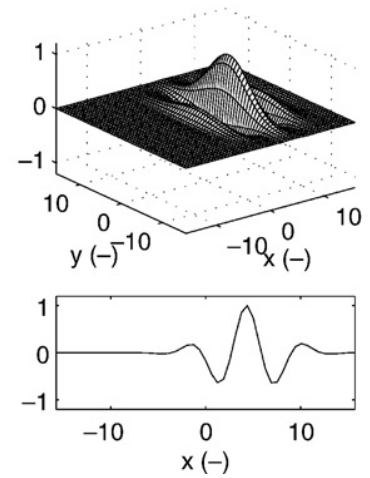

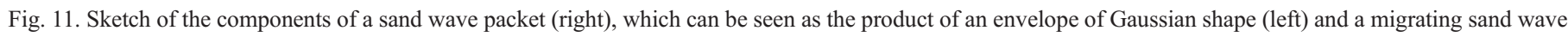

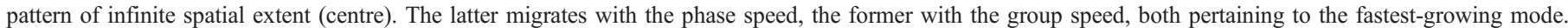

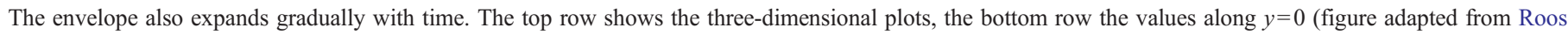
et al., 2005). 
The local disturbance is shown to develop gradually into a sand wave packet (Fig. 11), the horizontal area of which increases roughly linearly with time. The elevation at the packet's center tends to increase, but initially it may decrease depending on the spatial extent of the initial disturbance. In the case of tidal asymmetry, the individual sand waves in the packet migrate at the migration speed of the fastest-growing mode, whereas the packet's envelope moves at the group speed. The theoretical analysis is applied to trenches and pits, to show where the results differ from an earlier study of a time development of a trench in which sand wave dynamics was ignored.

\section{Conclusions}

The present review provides a description of some recent contributions to the study of the mechanisms underlying the formation and evolution of large-scale sedimentary patterns observed in the coastal region. These patterns are repetitive both in space and in time. The wavelength of these bottom forms (sand waves) is of a few hundreds of meters and the amplitude of a few meters. Sand waves are not static bedforms. Indeed, they migrate with a speed of a few meters per year. Even though simplifying assumptions have been introduced, the theoretical models provide fair predictions of the characteristics of the actual bottom forms and they can be used to solve practical problems.

Only the research carried out in the framework of the HUMOR project has been considered and the literature quoted above is by no means exhaustive.

\section{References}

Allen, J.R.L., 1984. Development in Sedimentology. Elsevier.

Besio, G., Blondeaux, P., Frisina, P., 2003. A note on tidally generated sand waves. J.Fluid Mech. 485, 171-190.

Besio, G., Blondeaux, P., Brocchini, M., Vittori, G., 2004. On the modelling of sand wave migration. J. Geophys. Res. Oceans 109 (C4). doi:10.1029/ 2002JC001622 C04018.

Besio, G., Blondeaux, P., Vittori, G., 2006. On the formation of sand waves and sand banks. J. Fluid Mech. 557, 1-27. doi:10.1017/S0022112006009256.

Blondeaux, P., 1990. Sand ripples under sea waves. Part I. Ripple formation. J. Fluid Mech. 218, 1-17.

Blondeaux, P., 2001. Mechanics of coastal forms. Annu. Rev. Fluid Mech. 33, 339-370.

Chen, Z., Bijker, R., 2001. Interactions of offshore pipelines and dynamic seabed. In: Li, G. (Ed.), Proceedings XXIX IAHR Congress, pp. 128-133. Beijing.

Colombini, M., Seminara, G., Tubino, M., 1987. Finite-amplitude alternate bars. J. Fluid Mech. 181, 213-232.

Dodd, N., Blondeaux, P., Calvete, D., De Swart, H., Falques, A., Hulscher, S.J.M.H., Rozynski, G., Vittori, G., 2003. The role of stability methods for understanding the morphodynamical behaviour of coastal systems. Cont. Shelf Res. 19, $849-865$.

Engelund, F., 1970. Instability of erodible beds. J. Fluid Mech. 42, 225-244.

Fluodas, C.A., Pardalos, P.M., 1996. State of Art in Global Optimization. Kluver Academic Publisher, Dordrecht. $651 \mathrm{pp}$.

Gerkema, T., 2000. A linear stability analysis of tidally generated sand waves. J. Fluid Mech. 417, 303-322.

Hulscher, S., Garlan, T., Idier, D., 2004. In: Hulscher, S., Garlan, T., Idier, D. (Eds.), Proceedings of: Marine Sand-Wave and River Dunes Dynamics II, International Workshop, April 1-2. University of Twente, the Netherlands, p. 352
Hulscher, S.J.M.H., 1996. Tidal-induced large-scale regular bedform patterns in a three-dimensional shallow water model. J. Geophys. Res. Oceans 101 (C9), 20727-20744.

Hulscher, S.J.M.H., Van de Brink, G.M., 2001. Comparison between predicted and observed sand waves and sand banks in the North Sea. J. Geophys. Res. Oceans 106 (C5), 9327-9338.

Idier D. 2002. Dynamics of continental shelf sandbanks and sand waves: in situ measurements and numerical modeling. PhD Thesis, National Polytechnical Institute, Toulouse Est., France, 314 pp.

Idier, D., Ehrhold, A., Garlan, T., 2002. Morphodynamics of an undersea sandwave of the Dover Straits C.R. Geosciences 334, 1079-1085.

Idier, D., Astruc, D., Hulscher, S.J.M.H., 2004. Influence of bed roughness on dune and megaripple generation. Geophys. Res. Lett. (ISSN: 0094-8276) L13214, 31. doi:10.1029/2004GL019969.

Katoh, K., Kume, H., Kuroki, K., Hasegawa, J., 1998. The development of sand waves and the maintenance of navigation channels in the Bisanseto Sea. Coastal Eng. '98. ASCE, Reston, VA, pp. 3490-3502.

Knaapen, M.A.F., 2005. Measuring sand wave migration in the field. Comparison of different data sources and an error analysis. J. Geophys. Res.-Earth Surface 110 (F4).

Knaapen, M.A.F., Hulscher, S.J.M.H., 2002. Regeneration of sand waves after dredging. Coast. Eng. 46, 277-289.

Knaapen, M.A.F., Hulscher, S.J.M.H., Vriend, H.J. de, Stolk, A., 2001. A new type of sea bed waves. Geophys. Res. Lett. 28 (7), 1323-1326.

Knaapen, M.A.F., Hulscher, S.J.M.H., Tiessen, M.C.H., van den Berg, J., 2005. Using a sand wave model for optimal monitoring of a navigation depth. In: Parker, G., Garcia, M.H. (Eds.), Proceedings forth IAHR Symposium on River, Coastal and Estuarine Morphodynamics 2005, Urbana, Illinois, USA, pp. 999-1007. RCEM 2005 IAHR

Komarova, N.L., Hulscher, S.J.M.H., 2000. Linear instability mechanism for sand wave formation. J. Fluid Mech. 413, 219-246.

Langhorne, D.N., 1982. A study of the dynamics of a marine sand wave. Sedimentology 29, 571-594.

Le Bot, S., Trentesaux, A., 2004. Types of internal structure and external morphology of submarine dunes under the influence of tide- and wind-driven processes (Dover Strait, northern France). Mar. Geol. 211, 143-168.

Le Bot, 2001. Morphodynamics of submarine dunes under the influence of tides and storms. PhD Thesis, University of Lille 1, France. , $272 \mathrm{pp}$.

Meyer-Peter, E., Müller, R., 1948. Formulas for bedload transport. III Conf. Int. Assoc. Hydraul. Res. Stockholm, Sweden.

Morelissen, R., Hulscher, S.J.M.H., Knaapen, M.A.F., Németh, A.A., Bi-jker, R., 2003. Mathematical modelling of sand wave migration and the interaction with pipelines. Coast. Eng. 48, 197-209.

Németh A.A. 2003. Modelling offshore sand waves. Ph.D. Thesis, University of Twente, The Netherlands.

Németh, A.A., Hulscher, S.J.M.H., 2003. Finite amplitude sand waves in shallow seas. In: Sánchez-Arcilla, A., Bateman, A. (Eds.), Proceedings Third IAHR Symposium on River, Coastal and Estuarine Morphodynamics 2003, Barcelona, Spain. ISBN: 90-805649-6-6, pp. 435-444. RCEM 2003 IAHR.

Németh, A.A., Hulscher, S.J.M.H., de Vriend, H.J., 2002. Modelling sand wave migration in shallow shelf seas. Cont. Shelf Res. 22, 2795-2806.

Németh, A.A., Hulscher, S.J.M.H., Vriend, H.J. de, 2003. Offshore sand wave dynamics, engineering problems and future solutions. Pipeline Gas J. 230, $67-69$.

Németh, A.A., Hulscher, S.J.M.H., Damme, R.M.J. van, 2006. Simulating offshore sand waves. Coast. Eng. 53, 265-275.

Németh, A.A., Hulscher, S.J.M.H., Damme, R.M.J. van, 2007. Modelling offshore sandwave evolution. Cont. Shelf Res. 27 (5), 713-728 (ISSN 02784343)

Roos, P.C., Blondeaux, P., Hulscher, S.J.M.H., Vittori, G., 2005. Linear evolution of sandwave packets. J. Geophys. Res. 110, F04S14. doi:10.1029/ 2004JF000196.

Schielen, R., Doelman, A., de Swart, H.E., 1992. On the nonlinear dynamics of free bars in straight channels. J. Fluid Mech. 252, 325-356.

Seminara, G., 1998. Stability and morphodynamics. Mecc. 33, 59-99.

Sleath, J.F.M., 1976. On rolling grain ripples. J. Hydraul. Res. 14, 69-81.

Stride, A.H., 1982. Offshore Tidal Sands (Processes and Deposits). Chapman and Hall. 
Trentesaux, A., Garlan, T. (Eds.), 2000. Marine Sandwave Dynamics (Dynamique des dunes sous-marines). Proceedings of an International Workshop, March 23-24 2000. University of Lille 1, France. ISBN: 2-11-088263-8, p. 240.

Van der Veen, H.H., Hulscher, S.J.M.H., Knaapen, M.A.F., 2006. Grain size dependency in the occurrence of sand waves. Ocean Dynamics 56, 228-234 (ISSN 1616-7341). doi:10.1007/s10236-005-0049-7.
Vittori, G., 1989. Nonlinear viscous oscillatory flow over a small amplitude wavy wall. J. Hydraul. Res. 27, 267-280.

Vittori, G., Blondeaux, P., 1990. Sand ripples under sea waves. Part II. Finiteamplitude development. J. Fluid Mech. 218, 19-39. 